\title{
The Roles of Ubiquitination Factor E4B (UBE4B) in the Postoperative Prognosis of Patients with Renal Cell Carcinoma and in Renal Tumor Cells Growth and Metastasis
}

This article was published in the following Dove Press journal: OncoTargets and Therapy

\author{
Xu-Qiong Huang ${ }^{1, *}$ \\ Shuai Hao',* \\ Zi-Qi Zhou ${ }^{2}$ \\ Bin Huang' \\ Jia-Ying Fang' \\ Yan Tang ${ }^{2}$ \\ Jian-Hua Zhang ${ }^{3}$ \\ Jian-Chuan $\mathrm{Xia}^{2}$ \\ 'Huadu District People's Hospital of \\ Guangzhou, Southern Medical University, \\ Guangzhou, Guangdong Province, \\ People's Republic of China; ${ }^{2}$ State Key \\ Laboratory of Oncology in Southern \\ China, Sun Yat-Sen University Cancer \\ Center, Guangzhou, Guangdong \\ Province, People's Republic of China; \\ ${ }^{3}$ Department of Health Service \\ Management, Guangzhou University of \\ Chinese Medicine, Guangzhou, \\ Guangdong Province, People's Republic \\ of China \\ *These authors contributed equally to \\ this work
}

Correspondence: Jian-Chuan Xia State Key Laboratory of Oncology in

Southern China, Sun Yat-Sen University

Cancer Center, 65I Dong-Feng Road

East, Guangzhou 510060, People's

Republic of China

Tel +86-20-87343।73

Fax +86-20-87343392

Email xiajch@mail.sysu.edu.cn

Jian-Hua Zhang

Department of Health Service

Management, Guangzhou University of

Chinese Medicine, 232 Wai-Huan Road

East, Guangzhou 510006, People's

Republic of China

Tel/Fax +86-20-39358999

Email zhangjh1962@hotmail.com
Object: This study aimed at investigating the clinical significance and biological function of ubiquitination factor E4B (UBE4B) in human renal cell carcinoma (RCC).

Methods: 19 paired clear cell renal cell carcinoma (ccRCC) tumor samples and the matched neighboring non-tumor samples were used to detect the expression of UBE4B in RCC tumor by Western blotting and RT-qPCR. UBE4B expression was also detected in $151 \mathrm{ccRCC}$ paraffin-embedded tumor samples by using immunohistochemistry. Overall survival (OS) in different UBE4B expression groups were compared with Log rank test. The prognostic value of UBE4B expression in OS was evaluated with the univariate and multivariate Cox regression models. UBE4B was knocked down by small interfering RNA (siRNA) technology, and the effect of UBE4B on cell proliferation, colony formation, metastasis, apoptosis and cell cycle of RCC cells were examined in vitro.

Results: Both protein and mRNA levels of UBE4B were up-regulated in ccRCC tumor tissues in contrast to the corresponding adjacent nontumor ones. UBE4B expression was positively associated with tumor-node-metastasis (TNM) stage and distant metastasis in ccRCC patients. Survival analyses indicated that low expression of UBE4B was associated with increased OS in ccRCC patients. Functional analyses demonstrated that siRNA silencing of UBE4B expression in SKRC39 and ACHN cells further reduced the growth, motility and invasiveness of RCC cells. Moreover, siRNA silencing of UBE4B in the RCC cell lines did not induce apoptosis, and an increase in the cell population was observed during the $\mathrm{G}_{0} / \mathrm{G}_{1}$ phase of the cell cycle.

Conclusion: UBE4B might act as an oncogene in regulating RCC development. Therefore it could be served as an effective indicator to predict OS and a potential biomarker for targeted therapy of RCC patients.

Keywords: renal cell carcinoma, UBE4B, prognosis, oncogene

Renal cell carcinoma (RCC) is a fatal genitourinary malignancy, and the most common adult kidney cancer. ${ }^{1,2}$ Regarded as effective curative therapies for RCC, nephrectomy and radiotherapy offer the opportunity of favorable long-term prognosis for early RCC patients. In addition, RCC is sensitive to immunotherapy and targeted therapy while highly resistant to both radiotherapy and chemotherapy. ${ }^{3}$ Nevertheless, more than $20 \%$ of patients with localized RCC suffer from tumor recurrence or progress to metastasis after nephrectomy, ${ }^{4,5}$ and it still causes nearly 120,000 deaths each year worldwide. ${ }^{6,7}$ Apart from that, the molecular mechanism 
involved in the pathogenesis of RCC has not been clarified yet. Hence, a novel molecular marker suitable for early diagnosis and more effective targeted therapy to ameliorate the outcome of RCC patients are urgently needed.

The ubiquitination factor E4B gene (UBE4B), also referred to as UFD2a, is one of the two human homolog of the UFD2 yeast gene. ${ }^{8,9}$ UBE4B is located in chromosome $1 \mathrm{p} 36$ and encodes ubiquitin conjugation factor E4 that is involved in multiubiquitin chain assembly. ${ }^{10,11}$ Ubiquitination is critical in cell functions such as proliferation, apoptosis, cell cycle regulation and DNA repair, and deregulation of certain types of protein that are involved in the tumorigenesis of many types of tumor. ${ }^{12,13}$ E4 is a key newly discovered class of ubiquitination enzyme during protein ubiquitination. Generally, dysfunction of anti-oncogene, e.g.p53, is crucial during tumor progression. ${ }^{14-16}$ Recent studies showed that UBE4B facilitated the polyubiquitination and degeneration of p53. ${ }^{17-20}$ Moreover, UBE4B aberrant expression has been reported in several kinds of cancers, such as breast cancer, ${ }^{21}$ promyelocytic leukemia $^{22}$ and nasopharyngeal carcinoma. ${ }^{23}$ Our previous study also demonstrated that UBE4B overexpression promoted the tumorigenesis of hepatocellular carcinoma (HCC) and was related to a poor outcome in HCC patients. ${ }^{24}$ As far as we know, the expression and prognostic value of UBE4B in tumorigenesis of RCC has not been clarified yet.

Aiming to reveal the clinical value of UBE4B in RCC, the expression and prognostic values of UBE4B in RCC was investigated. Additionally, the effect of UBE4B in RCC progression was also evaluated by using different RCC cell lines.

\section{Materials and Methods}

\section{Human Clinical Samples}

Since clear cell renal cell carcinoma (ccRCC) comprises approximately $75 \%$ of RCC in surgical series, ${ }^{25,26} \mathrm{ccRCC}$ subtype was selected to be the research subject. $151 \mathrm{ccRCC}$ patients who had undergone nephrectomy without preoperative radiotherapy or chemotherapy were selected from the Sun
Yat-sen University Cancer Center (SYSUCC) between 2012 and 2014, and their corresponding paraffin-embedded tumor samples were obtained. All the RCC patients' postoperative histopathology diagnosis were confirmed as ccRCC by qualified Pathologists based on World Health Organization (WHO) classification standard, ${ }^{27}$ and their pathological grading were graded following the nuclear grading system (Fuhrman et al 1982). ${ }^{28}$ The TNM stage was staged by radiographic findings and postoperative pathological data according to 2010 American Joint Committee on Cancer (AJCC) TNM classification. ${ }^{29}$ The patient demographics and followup data were obtained from the follow-up center of SYSUCC. Overall survival (OS) was employed as an index to evaluate the prognosis, and it was defined as the time from the date of operation to death or the latest follow-up. In addition, 19 paired ccRCC tumor samples and the matched neighboring non-tumor samples were acquired from ccRCC patients undergoing surgical resection at SYSUCC in 2015.

\section{Cell Lines}

Five human RCC cell lines (786-O, CaKi-1, SKRC39, $\mathrm{ACHN}$ and A498) were acquired from the American Type Culture Collection (ATCC, Rockville, MD, USA). All the cells were cultured in RPMI1640 medium (Gibco, Grand Island, NY, USA) added with 10\% FBS (Gibco, Grand Island, NY, USA) and $1 \%$ penicillin-streptomycin in $5 \%$ $\mathrm{CO}_{2}$ humidified atmosphere at $37^{\circ} \mathrm{C}$.

\section{Cell Transfection with Small Interfering RNA (siRNA)}

As shown in Table 1, four siRNAs (siUBE4B \#1-4) and a negative control (siNC) were purchased from GenePharma (GenePharma, Suzhou, China). The siUBE4B and siNC were transfected transiently into SKRC39 and ACHN cells via Lipofectamine 2000 (Invitrogen, Carlsbad, CA,USA) based on the product's specification. The transfected cells were named as SKRC39/siUBE4B, SKRC39/siNC, ACHN/siUB $\mathrm{E} 4 \mathrm{~B}$, and $\mathrm{ACHN} / \mathrm{siNC}$, respectively.

Table I Small Interfering RNA (siRNA) Sequences That Target Ubiquitination Factor E4B (siUBE4B) and Negative Control siRNA (siNC)

\begin{tabular}{|l|l|l|}
\hline siRNA & Sense Sequence & Anti-Sense Sequence \\
\hline siUBE4B \#I & 5'-GCCCUCUAAUAGCCUUGAATT-3' & 5'-UUCAAGGCUAUUAGAGGGCTT-3' \\
siUBE4B \#2 & 5'-GACAGUGACUACUUUAAAUTT-3' & 5'-AUUUAAAGUAGUCACUGUCTT-3' \\
siUBE4B \#3 & 5'-GCAGUUUGUUCGCUAUAUATT-3' & 5'-UAUAUAGCGAACAAACUGCTT-3' \\
siUBE4B \#4 & 5'-CUGCAAUGCUGAACUUUAATT-3' & 5'-UUAAAGUUCAGCAUUGCAGTT-3' \\
siNC & 5'-UUCUCCGAACGUGUCACGUTT-3' & 5'-ACGUGACACGUUCGGAGAATT-3' \\
\hline
\end{tabular}




\section{Real-Time Quantitative PCR (RT-qPCR)}

Firstly, total RNA was extracted from RCC tissues utilizing TRIzol (Invitrogen, Carlsbad, CA, USA). Then, each sample's total RNA was reversely transcribed to cDNA utilizing the ReverTraAce qPCR RT Kit (TOYOBO, Shanghai, China) following the product's specification. The target cDNA was amplified by realtime PCR employing the SYBR Green Realtime PCR master mix (Invitrogen, Carlsbad, CA,USA). The comparative threshold cycle $\left(2-{ }^{\Delta \Delta C T}\right)$ method was applied to quantify the relative transcript levels of the UBE4B gene which was normalized by the corresponding values of glyceraldehyde-3-phosphate dehydrogenase (GAPDH). The sequences of all primers used were as follows: the reference gene, GAPDH, forward 5'-CTCCTCCTGTTCGACAGTC AGC-3'， reverse 5'-CCCAATACGACCAAATCCGTT-3'; the target gene, UBE4B, forward 5'-CCAAAGAAGCTG TTGGACCAACTG-3', reverse 5'-GGGTGTCCATCAGAG GGTCTCTG-3'.

\section{Western Blotting}

Radio-Immunoprecipitation Assay (RIPA) Lysis Buffer (Beyotime, Shanghai, China) was used to extract total proteins. The concentration of total proteins was determined using the BCA Protein Assay Kit (Bio-Rad; Hercules, CA, USA), and the optical density (OD) was recorded at $562 \mathrm{~nm}$ by a microplate spectrophotometer (EPOCH2, Bio-Tek, Winooski, USA). Western blotting and the quantification of band intensity were performed as described previously. ${ }^{30}$ The following antibodies were applied: rabbit polyclonal antibody against UBE4B (1:1000 dilution; Proteintech, Chicago, IL, USA, Catalogue number:18148-1-AP), rabbit anti-GAPDH polyclonal antibody (1:10,000 dilution, Proteintech, Chicago, IL, USA, Catalogue number: 10494-1-AP) and anti-rabbit $\mathrm{IgG}$, horseradish peroxidase (HRP)-conjugated secondary antibody (1:2000 dilution, Cell Signaling Technology, Danvers, MA, USA, Catalogue number: 7074S). The UBE4B protein expression levels were normalized to that of GAPDH.

\section{Immunohistochemistry Analysis}

Serial $2 \mu \mathrm{m}$ sections that cut from 151 ccRCC paraffinembedded samples were used for UBE4B immunohistochemistry. Rabbit polyclonal antibody against UBE4B (1:200 dilution; Proteintech, Chicago, IL, USA, Catalogue number: 18148-1-AP) and anti-Mo\&Rb IgG, HRP-conjugated secondary antibody (Envision ${ }^{\mathrm{TM}}$ Detection Kit, Gene Tech, Shanghai, China, Catalogue number:GK500705) were applied. Immunohistochemistry staining and a semiquantitative scoring criterion for the assessment of UBE4B immunostaining degree were performed as indicated in our previous study. ${ }^{30}$ For negative controls, tissue sections were immunoreacted with PBS under the same experimental conditions. The quantification of UBE4B expression levels in ccRCC paraffin-embedded samples were evaluated according to the staining intensity and the positively stained areas of tumor cells by 2 independent pathological professionals (HXQ and ZZQ) who were blinded to the clinicopathological parameters under a light microscope (Nikon, ECLIPSE E100, Japan). If the two evaluations of one sample were different, a third pathologist would participate to determine the final evaluation. The semi-quantitative scoring criterion was as follows: the percent of positive staining was defined as 0 ( $<5 \%$, negative), 1 (5\%-25\%, sporadic), $2(25 \%-50 \%$, focal), or 3 ( $>50 \%$, diffuse); staining intensity was classified as 0 (no staining), 1 (weak staining), 2 (moderate staining) and 3 (strong staining). The two values were multiplied to give sum scores of the immunostaining between 0 and 9. These were used to define the expressions of UBE4B as follows: "--" (score $0-1)$, “+” (score 2-3), “++” (score 4-5) or “+++" ( $>6$ points). The sampled patients were divided into low UBE4B expression (UBE4B- or UBE4B+) or high UBE4B expression groups (UBE4B++ or UBE4B+++).

\section{Proliferation Assay}

A density of 800 transfected cells per well were plated and cultured in 96-well plates. Cell proliferation was evaluated for 7 consecutive days using the methanethiosulfonate (MTS) assay. In brief, $20 \mu \mathrm{L}$ MTS reagent $(5 \mathrm{mg} / \mathrm{mL}$, Sigma-Aldrich, Shanghai, China) was added to the plated cells and the optical density (OD) was recorded at $490 \mathrm{~nm}$ by a spectrophotometric reader (EPOCH2, Bio-Tek, Winooski, USA) after 3 hrs' incubation. All experiments were repeated in triplicate.

\section{Colony Formation Assay}

A density of 1000 transfected cells per well were plated and cultured in 6-well plates in triplicate. After 12 days, the living cells were fixed and stained. The colonyforming efficiency was evaluated as our previous study. ${ }^{30}$

\section{Cell Cycle Analysis}

To determine cell cycle distribution, the targeted cells were preprocessed and treated with cell cycle detection kit (Bestbio, Shanghai, China) according to the product's specification. DNA content of cells was tested using a flow 
A

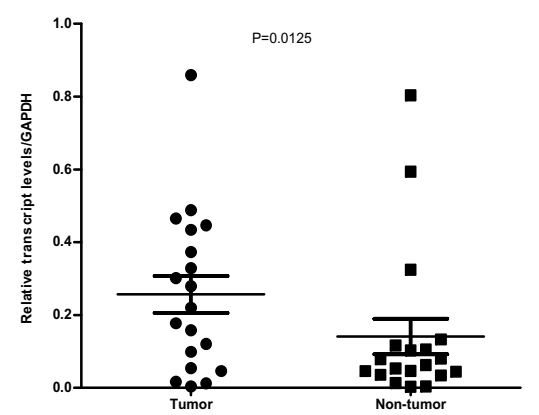

B

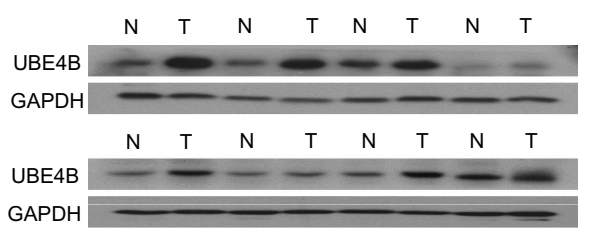

C

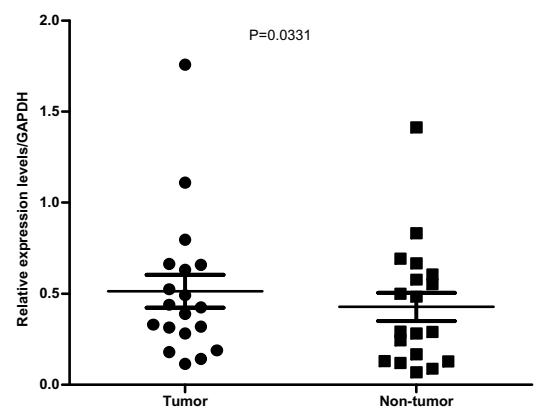

Figure I Expression of UBE4B mRNA and protein in human ccRCC surgical specimens was evaluated by RT-qPCR and Western blotting. (A) RT-qPCR revealed that the relative expression of UBE4B was significantly higher in tumor tissues compared to the matched adjacent non-cancerous tissues $(n=19 ; P=0.0125)$. (B) Representative Western blotting analysis of UBE4B protein expression in eight paired ccRCC tissues and the matched adjacent non-cancerous tissues ( $\mathbf{N}$, matched non-cancerous tissues; T, ccRCC tissues). (C) Relative UBE4B protein expression was higher in tumor tissues than the matched adjacent non-tumor tissues $(n=19 ; P=0.0331)$.

cytometry (Beckman Coulter, Fullerton, CA, USA). Cell Quest and ModFit software (Beckman Coulter) were used to calculate the proportion of cells at different cell cycle phase. All experiments were conducted in triplicate.

\section{Apoptosis Assay}

The Annexin V-FITC Apoptosis Detection Kit (BD Biosciences, Bedford, MA, USA) was used to examine

A

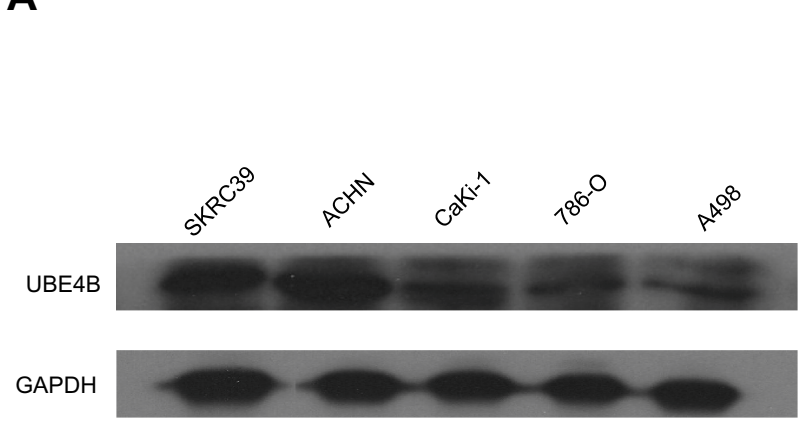

C

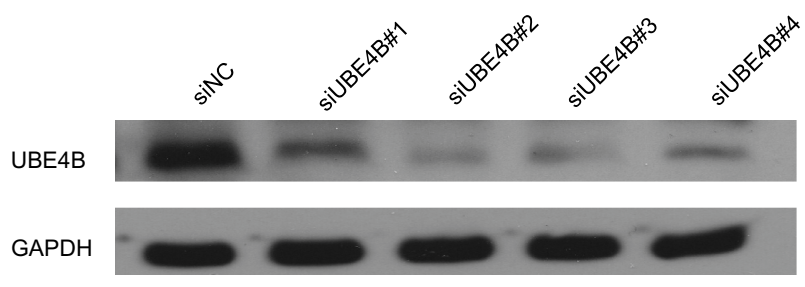

SKRC39 the apoptosis rates of cells following the product's instruction by flow cytometry (Beckman Coulter, Fullerton, CA, USA). The experiments were repeated three times.

\section{Cell Migration and Invasion Assays in vitro}

$2 \times 10^{5}$ cells (migration) or $3 \times 10^{5}$ cells (invasion) were resuspended in $200 \mu \mathrm{L}$ RPMI 1640 without serum and planted in
Figure 2 Expression of UBE4B protein in RCC cell lines by Western blotting. (A) Representative Western blotting of UBE4B protein expression in five human RCC cell lines. (B) Expression of UBE4B protein in human RCC cell lines was upregulated in ACHN, A498, 786-O, CaKi-I and SKRC39 cells. Relative protein levels of UBE4B in different cell lines were shown as mean \pm SD. (C, D) Among the four UBE4B-targeted small interfering RNAs (siUBE4B), siUBE4B\#2 and siUBE4B\#3 showed higher knockdown efficiencies after 48 hrs' transfection. siNC represents negative control small interfering RNAs.
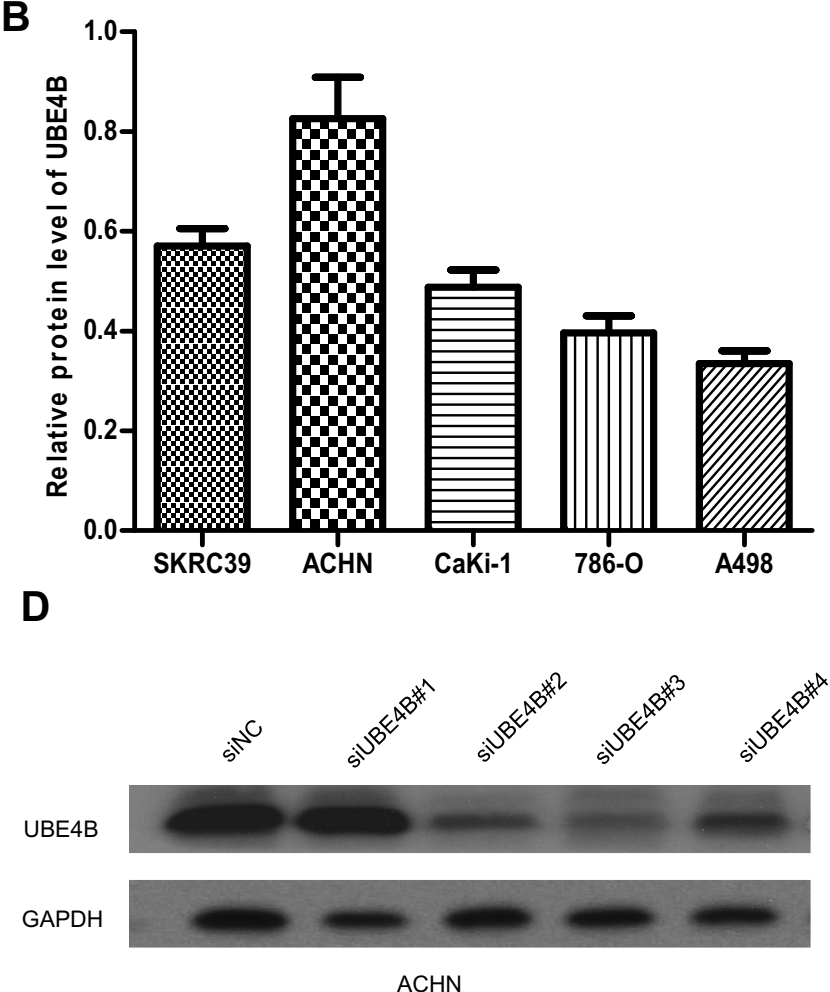
pore polycarbonate membrane inserts $(8 \mu \mathrm{m}$, Corning Incorporated, Corning, NY, USA) with or without a filmy coating of Matrige $(0.5 \mathrm{mg} / \mathrm{mL}, \mathrm{BD}$, Franklin Lakes, NJ, USA) respectively. Then, the inserts were placed on 24well plates which contained $500 \mu \mathrm{L}$ RPMI 1640 with $10 \%$ FBS. The above cells were cultured for $24 \mathrm{~h}$ (migration) or 48 $\mathrm{h}$ (invasion), and then, the cells on the reverse side of membrane were fixed and stained. After that, cotton swabs were applied to remove cells on the surface of the membrane, and five random microscopic fields of each membrane were selected to count the stained cells by microscopy. All experiments were repeated three times.

\section{Statistical Analysis}

Data analysis in this study was realized with SPSS software 21.0 (SPSS Inc., Chicago, IL, USA). The Pearson's $X^{2}$ test was used for qualitative variables.and the Student's $t$-test was applied for quantitative variables to assess the correlations between UBE4B expression and the baseline variables of RCC patients. OS in different UBE4B expression groups were compared with Log rank test. The prognostic value of UBE4B expression in OS was evaluated with the univariate and multivariate Cox regression models. Two-sided $P<0.05$ was considered as statistical significance.

\section{Results}

\section{The Expression of UBE4B in RCC Samples and RCC Cell Lines}

RT-qPCR was applied to determine the mRNA levels of UBE4B in 19 pairs of RCC tissues and the matched nontumor tissues. Compared with the corresponding non-tumor tissues, the mRNA levels of UBE4B were remarkably up-regulated in $14 / 19(73.7 \%)$ RCC tissues ( $P=0.0125$; Figure 1A). Similar to the RT-qPCR results, the protein expression levels of UBE4B were remarkably higher in 15/19 (78.9\%) of the RCC tissues than the corresponding nontumor tissues $(P=0.0331$; Figure $1 \mathrm{~B}$ and $\mathrm{C}$ ).

UBE4B expression was tested in five human RCC cell lines so as to choose the most suitable cells to be transfected. Relatively higher expression of UBE4B was found in SKRC39 and ACHN cells than the other cell lines examined by Western blotting (Figure $2 \mathrm{~A}$ and B). Accordingly, SKRC39 and ACHN were selected as the optimal cells to be transfected with four targeting-siRNAs (siUBE4B\#1-4).
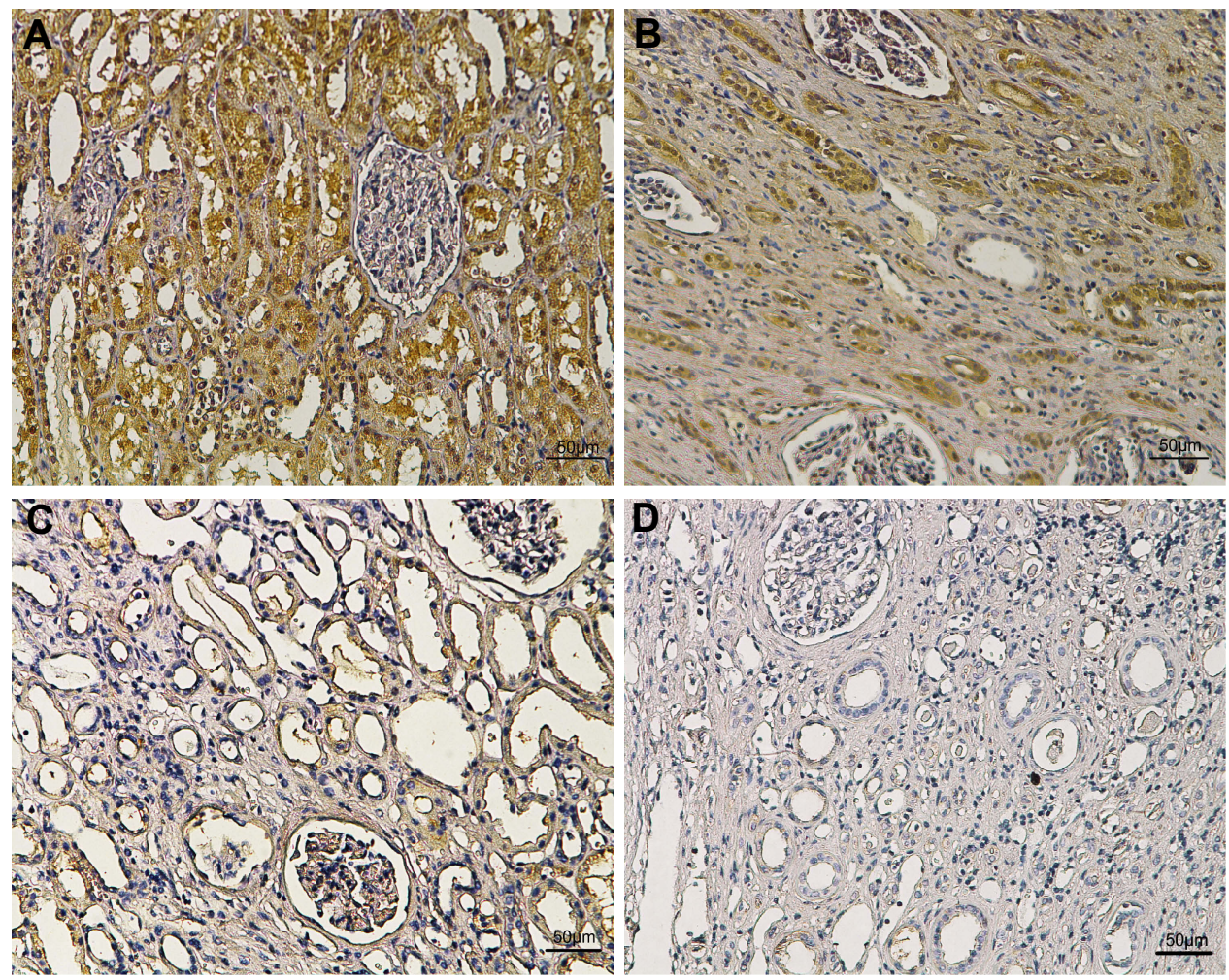

Figure 3 Representative immunohistochemical images of different staining intensity in $\mathrm{CcRCC}$ and surrounding non-tumor tissues. (A) Strong UBE4B staining in ccRCC tissues. (B) Intermediate UBE4B staining in ccRCC tissues. (C) Weak UBE4B staining in ccRCC tissues. (D) Negative staining in surrounding non-tumor tissues. Scale bars: $50 \mu \mathrm{m}$. Original magnification: $\times 100$. 
After 48 hrs' transfection, the knockdown efficiency of UBE4B was assessed by Western blotting. The outcomes suggested that the level of UBE4B expression was inhibited efficiently in both cell lines transfected with either siUBE4B \#2 or siUBE4B \#3 (Figure 2C and D).

\section{Immunohistochemical UBE4B Intensity and Its Association with the Baseline Variables of RCC Patients}

To explore the clinical significance of UBE4B in RCC, the relationship between the expression of UBE4B and baseline features were examined. As indicated in Figure 3, the positive staining of UBE4B was mostly distributed in the cell membrane and/or cytoplasm. The 151 patients were divided into the high UBE4B expression group $(n=72)$ or low UBE4B expression group $(n=79)$. The relationship between UBE4B expression and the baseline variables of RCC were shown in Table 2. $X^{2}$ test analyses revealed that UBE4B expression in RCC tissues was obviously associated with TNM stage $(P<0.001)$. Moreover, the higher incidence of distant metastases was observed in the high UBE4B expression group $(P=0.005)$, and none of other baseline features were related to UBE4B expression.

\section{Association of UBE4B Expression with RCC Patient Survival}

The relationship between UBE4B expression and patient survival was analyzed to assess the prognostic value of UBE4B expression in RCC patients. Kaplan-Meier analyses indicated that worse OS was found in patients of the UBE4B high expression group $(P<0.001$, Figure 4A). Univariate Cox regression analyses revealed that gender $(P=0.036)$, tumor sizer $(P=0.012)$, histological grade $(P=0.036)$, UBE4B expression $(P=0.001)$ and distant metastasis $(P<0.001)$ were all remarkable risk factors (Table 3). Multivariate Cox regression analyses showed that high UBE4B expression was an independent factor of poor outcome in RCC patients ( $P=0.034$, Table 3$)$.

To further prove the prognostic value of UBE4B expression in RCC, subgroup analysis based on several clinical variables was conducted. The prognostic value of UBE4B expression was analyzed when patients were grouped based on Fruhman grade, Renal capsular invasion (RCI) and distant metastasis (DM). We found that high and low UBE4B expression groups displayed remarkably different OS according to Fruhman grade (Figure 4B and C), DM (Figure 4D) and RCI (Figure 4E and F). On the whole, these findings showed that UBE4B expression could effectively predict the outcome of RCC patients.

\section{Effect of UBE4B on the Growth of RCC Cells}

Cell proliferation and colony formation assays were carried out to find out whether UBE4B could influence tumor growth in vitro. SKRC39/siUBE4B and ACHN/siUBE4B cells showed inhibited proliferation (all $P<0.05$, Figure 5A and $\mathrm{B}$ ) and colony-forming abilities compared with SKRC39/siNC and ACHN/siNC cells (all $P<0.001$, Figure 5C and D). These findings revealed that UBE4B may enhance the growth of RCC cells in vitro.

Table 2 Relationship Between UBE4B Expression and Clinic Pathological Features of Patients with ccRCC

\begin{tabular}{|c|c|c|c|}
\hline \multirow[t]{2}{*}{ Variables } & \multicolumn{2}{|c|}{ UBE4B Expression } & \multirow[t]{2}{*}{$P$ value } \\
\hline & $\operatorname{Low}(79)$ & High(72) & \\
\hline Mean $\pm S D$ age (years) & $49.1 \pm 12.2$ & $52.4 \pm 13.2$ & 0.114 \\
\hline Gender & & & 0.274 \\
\hline Male & 56 & 45 & \\
\hline Female & 23 & 27 & \\
\hline Tomor size $(\mathrm{cm})$ & & & 0.816 \\
\hline$<5$ & 41 & 36 & \\
\hline$\geq 5$ & 38 & 36 & \\
\hline Mean \pm SD serum AFP(ug/l) & $2.52 \pm 1.66$ & $2.54 \pm 1.67$ & 0.919 \\
\hline Fuhrman grade & & & 0.177 \\
\hline Clear cell I - II & 69 & 57 & \\
\hline Clear cell III-IV & 10 & 15 & \\
\hline TNM Staging & & & $0.00 I^{*}$ \\
\hline I - II & 74 & 53 & \\
\hline III-IV & 5 & 19 & \\
\hline Hematuria & & & 0.939 \\
\hline Negative & 50 & 46 & \\
\hline Positive & 29 & 26 & \\
\hline Albuminuria & & & 0.644 \\
\hline Negative & 70 & 62 & \\
\hline Positive & 9 & 10 & \\
\hline Distant metastasis & & & $0.005^{*}$ \\
\hline Yes & 5 & 16 & \\
\hline No & 74 & 56 & \\
\hline Renal capsular invasion & & & 0.871 \\
\hline Yes & 38 & 36 & \\
\hline No & 41 & 36 & \\
\hline
\end{tabular}

Note: $* P<0.05$ was considered statistically significant.

Abbreviations: AFP, alpha-fetoprotein; SD, standard deviation. 
A

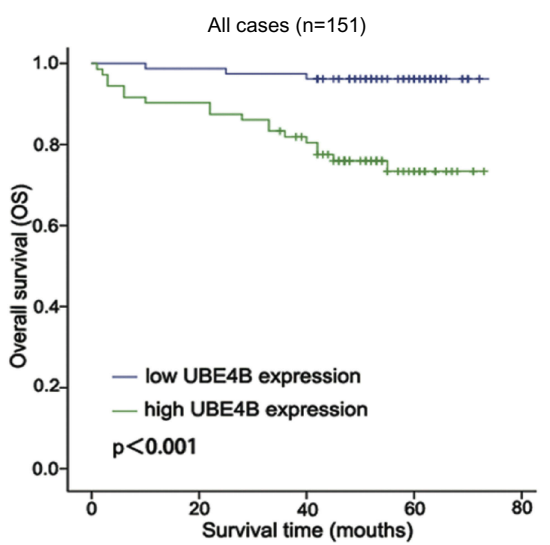

D

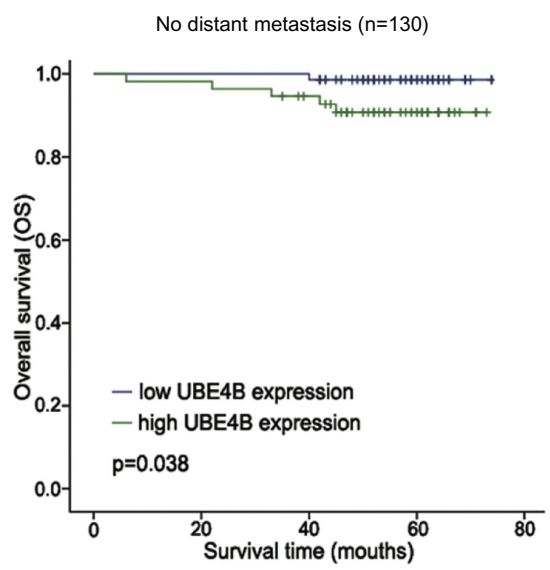

B

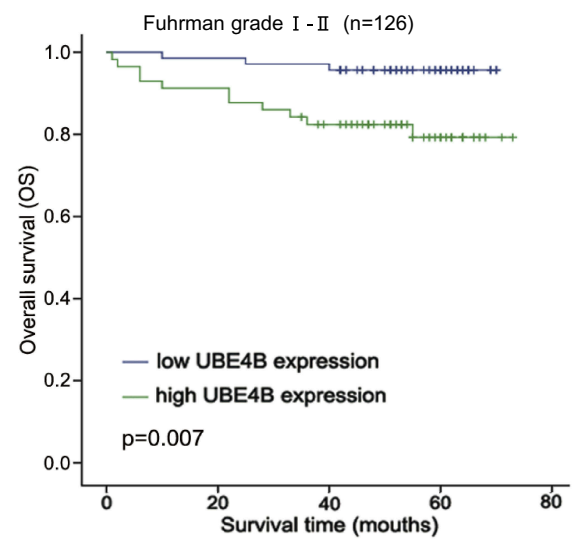

E

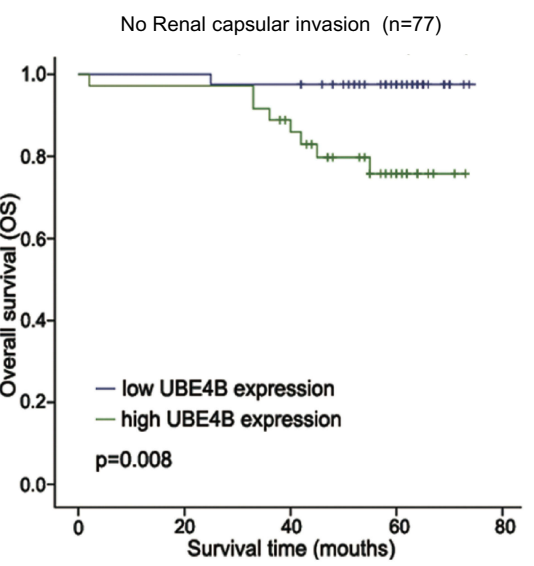

C

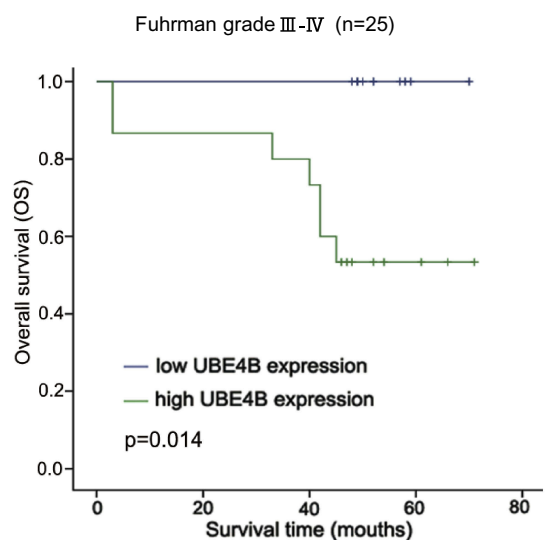

F

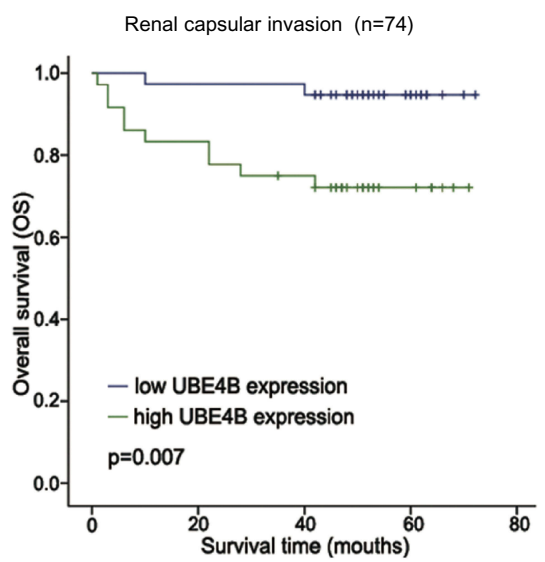

Figure 4 Analysis of overall survival (OS) for patients with ccRCC stratified by UBE4B expression. (A) Kaplan-Meier analysis of OS of all cases ( $n=151)$. (B) OS for the subgroup with Fuhrman grade I-II $(n=126)$. (C) OS for the subgroup with Fuhrman grade III-IV $(n=25)$. (D) OS for the subgroup with no Distant metastasis $(n=130)$. (E) OS for the subgroup with no Renal capsular invasion $(n=77)$. (F) OS for the subgroup with Renal capsular invasion $(n=74)$. $P$-values were calculated using the Log rank test.

\section{Effect of UBE4B in Cell Cycle and Apoptosis in RCC Cells}

Apoptosis and cell cycle analyses were performed to examine whether the UBE4B knockdown-mediated inhibition of RCC cells growth is related to cell cycle arrest or an induction of apoptosis. Results revealed that knockdown of UBE4B in SKRC39 and ACHN cells resulted in more percentages of cells in the $\mathrm{G}_{0} / \mathrm{G}_{1}$ phase and fewer percentages of cells in the $\mathrm{S}$ phase $(P<0.05$, Figure $6 \mathrm{~A}$ and $\mathrm{B})$, and no remarkable differences were found in the percentages of apoptotic cells between RCC cells transfected with siUBE4B and those transfected with siNC (both $P>0.05$, Figure $6 \mathrm{C}$ and $\mathrm{D}$ ).

\section{Effect of UBE4B on the Metastasis of RCC Cells}

Previous results indicated that UBE4B expression was obviously associated with tumor distant metastasis (Table 2).
Subsequent analyses were conducted to ascertain the effect on metastasis in RCC through Boyden chamber migration and Matrigel invasion assays. Transwell assay displayed that the metastasis ability of ACHN and SKRC39 cells transfected with siUBE4B were significantly suppressed compared to controlled cells (all $P<0.01$, Figure 7A-D).

\section{Discussion}

Recent findings on the role of UBE4B in the tumorigenesis of cancer are controversial. In this study, a series of ccRCC tissue samples were used to investigate UBE4B expression and its prognostic value in RCC patients. Meanwhile, a series of in vitro experiments were performed to clarify the potential mechanism of UBE4B in the progression of RCC. Our research showed that UBE4B expression was significantly upregulated at both transcriptional and translational levels of RCC tissues compared with the corresponding non-tumor tissues, which was similar to findings on breast cancer, ${ }^{21}$ nasopharyngeal carcinoma ${ }^{23}$ and hepatocellular carcinoma. ${ }^{24}$ 
Table 3 Univariate and Multivariate Analysis of Overall Survival in ccRCC

\begin{tabular}{|c|c|c|c|c|}
\hline \multirow[t]{2}{*}{ Variables } & \multicolumn{2}{|l|}{ Univariate Analysis } & \multicolumn{2}{|l|}{ Multivariate Analysis } \\
\hline & HR (95\% Cl) & $P$ value & HR $(95 \% \mathrm{CI})$ & $P$ value \\
\hline Age & $\begin{array}{l}1.009 \\
(0.974-1.046)\end{array}$ & 0.603 & - & - \\
\hline $\begin{array}{l}\text { Gender } \\
\left(\text { female vs Male }{ }^{a}\right)\end{array}$ & $\begin{array}{l}2.505 \\
(1.063-5.902)\end{array}$ & $0.036 *$ & $\begin{array}{l}2.374 \\
(0.884-6.089)\end{array}$ & 0.087 \\
\hline $\begin{array}{l}\text { Tumor size } \\
\left(\geq 5 \text { vs }<5 \mathrm{~cm}^{\mathrm{a}}\right)\end{array}$ & $\begin{array}{l}3.616 \\
(1.325-9.873)\end{array}$ & $0.012^{*}$ & $\begin{array}{l}2.374 \\
(0.690-8.165)\end{array}$ & 0.170 \\
\hline $\begin{array}{l}\text { Fuhrman grade } \\
\left(\text { III-IV vs. I - II }{ }^{\mathrm{a}} \text { ) }\right.\end{array}$ & $\begin{array}{l}2.642 \\
(1.065-6.559)\end{array}$ & $0.036 *$ & $\begin{array}{l}0.668 \\
(0.227-1.961)\end{array}$ & 0.668 \\
\hline $\begin{array}{l}\text { TNM stage } \\
(I I I+I V \text { vs I + II })\end{array}$ & $\begin{array}{l}|1.97| \\
(4.936-29.013)\end{array}$ & $<0.00 I^{*}$ & $\begin{array}{l}0.434 \\
(0.078-2.40 I)\end{array}$ & 0.339 \\
\hline AFP & $\begin{array}{l}0.918 \\
(0.686-1.229)\end{array}$ & 0.566 & - & - \\
\hline $\begin{array}{l}\text { Hematuria } \\
\text { (positive vs negative }{ }^{a} \text { ) }\end{array}$ & $\begin{array}{l}0.396 \\
(0.133-1.178)\end{array}$ & 0.096 & - & - \\
\hline $\begin{array}{l}\text { Albuminuria } \\
\text { (positive vs negative }{ }^{a} \text { ) }\end{array}$ & $\begin{array}{l}0.691 \\
(0.161-2.970)\end{array}$ & 0.620 & - & - \\
\hline $\begin{array}{l}\text { Renal capsular invasion } \\
\text { (positive vs negative }^{\mathrm{a}} \text { ) }\end{array}$ & $\begin{array}{l}0.343 \\
(0.640-3.615)\end{array}$ & 0.343 & - & - \\
\hline $\begin{array}{l}\text { UBE4B } \\
\text { (high vs low }{ }^{\mathrm{a}} \text { ) }\end{array}$ & $\begin{array}{l}7.477 \\
(2.201-25.396)\end{array}$ & $0.00 I^{*}$ & $4.470(1.121-17.829)$ & $0.034 *$ \\
\hline $\begin{array}{l}\text { Distant metastasis } \\
\text { (positive vs negative }^{a} \text { ) }\end{array}$ & $27.272(10.392-71.570)$ & $<0.001 *$ & $34.945(7.220-169.138)$ & $<0.001 *$ \\
\hline
\end{tabular}

Notes: $* P<0.05$ was considered statistically significant. ${ }^{a}$ Reference group.

Abbreviations: $\mathrm{HR}$, hazard ratio; $\mathrm{Cl}$, confidence interval; AFP, alfa fetoprotein; TNM, tumor, node, metastasis.

Immunohistochemical analysis also indicated that the upregulated UBE4B expression was remarkably associated with advanced TNM stage and distant metastasis. These findings indicated that UBE4B could be served as an oncogene in several kinds of cancers.

This study revealed that high UBE4B expression may be related to a poor clinical outcome in RCC patients. Moreover, multivariate analyses displayed that UBE4B expression was an independent prognostic indicator for OS. Similarly, our previous research had reported the relation between the magnifying expression of UBE4B and unfavorable prognosis in HCC. ${ }^{24}$ Conversely, studies by Zage et $\mathrm{al}^{31}$ and Sarah et $\mathrm{al}^{32}$ reported that low UBE4B expression was related to an unfavorable prognosis in patients with neuroblastoma. These findings implied that UBE4B might act as a new prognostic indicator for patients with various malignancies.
Previous studies have identified that Histological differentiation and Renal capsular invasion could be independent prognostic variables for ccRCC. ${ }^{33,34}$ Multivariate Cox regression analyses in this study indicated that distant metastasis was an independent prognostic factor in RCC. To further prove the prognostic value of UBE4B in RCC, we conducted subgroup analysis based on Fruhman grade, Renal capsular invasion and Distant metastasis. The results suggested that no matter with low or high Furhman Grade or other independent prognostic variables, RCC patients which demonstrated high UBE4B expression had poorer OS. All the results of survival analysis highlighted the expression of UBE4B could be an independent prognostic indicator for OS in RCC patients either with low or high tumor burden.

Considering that UBE4B has oncogenic potential, a string of functional studies in RCC cell lines in vitro were conducted to explore whether the reduction of UBE4B 
A
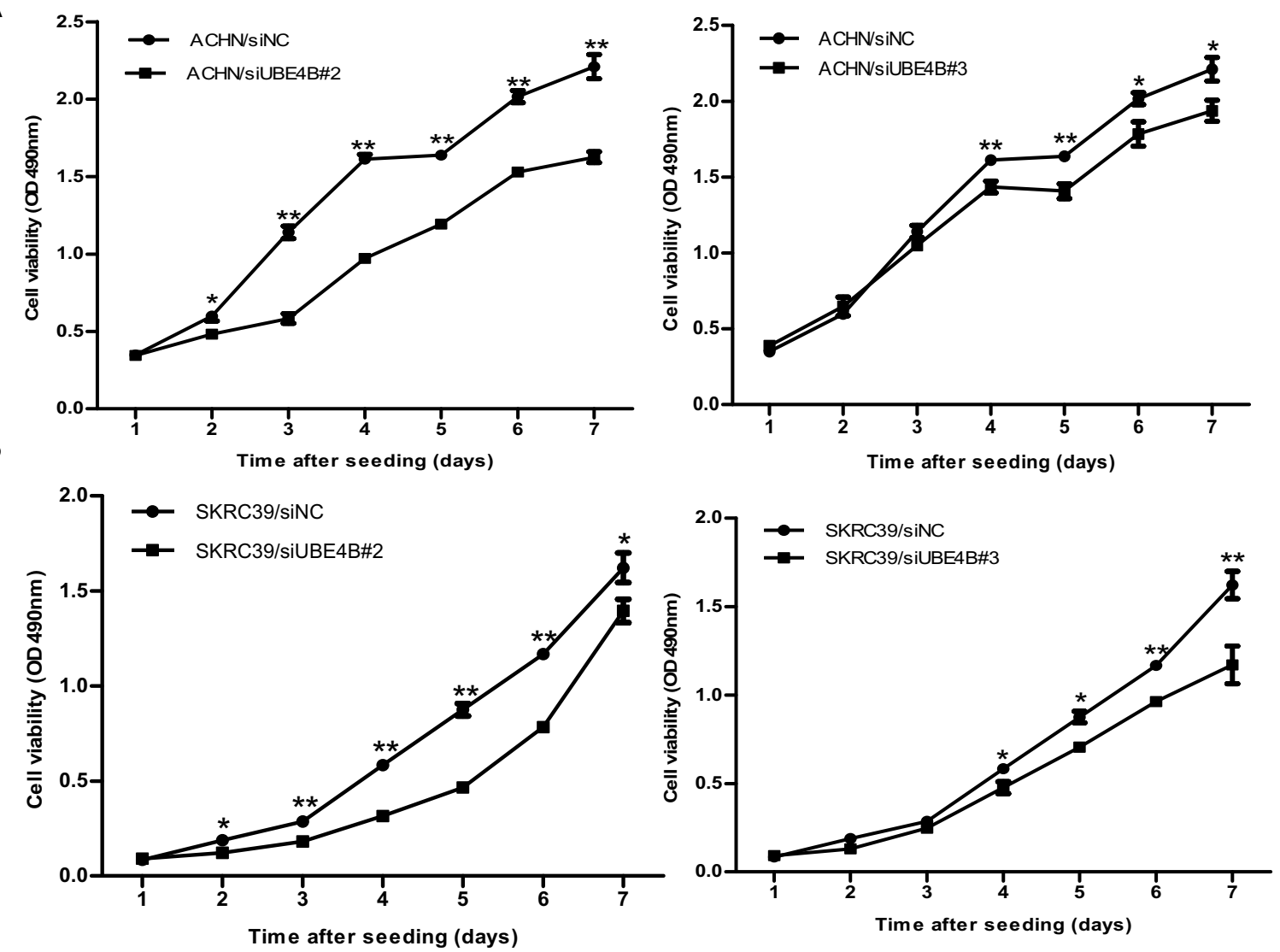

C
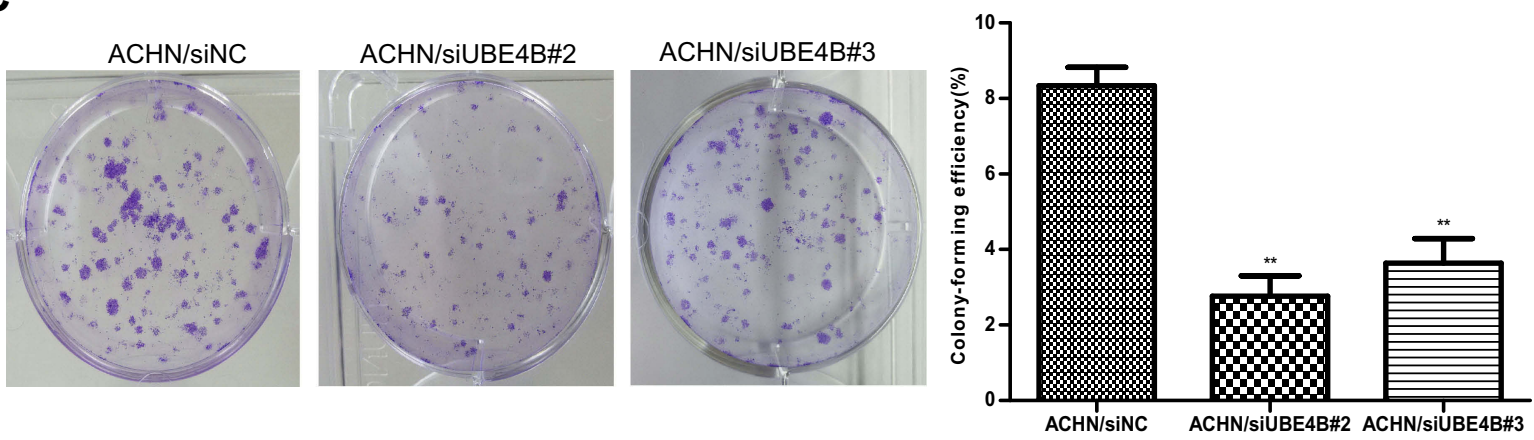

D
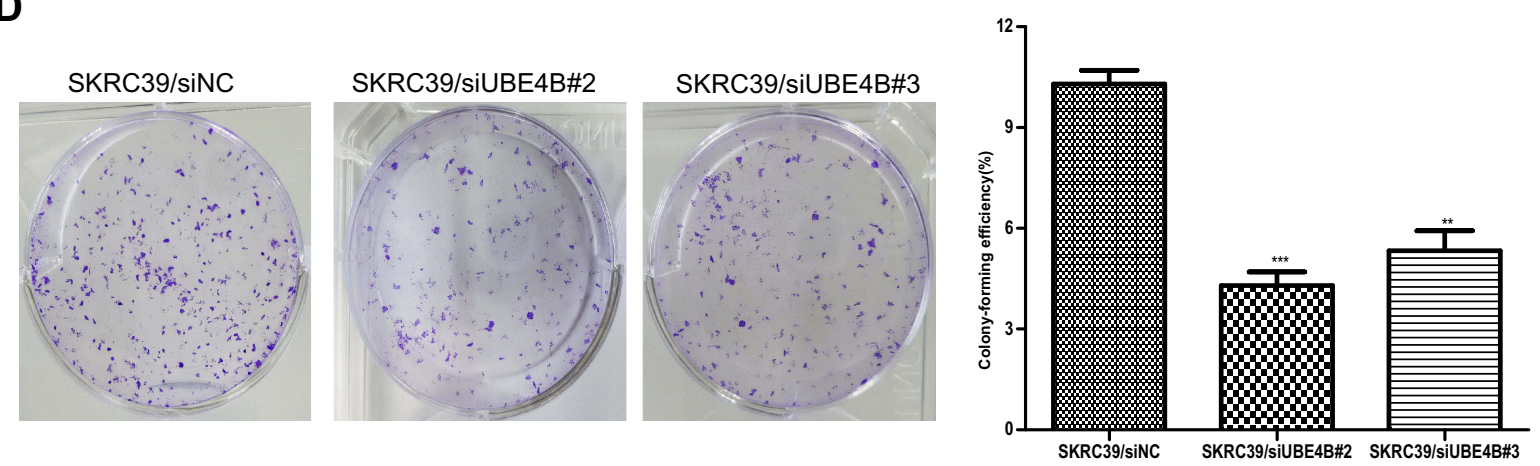

Figure 5 Inhibition of RCC cell growth ability by UBE4B silencing. (A, B) Proliferation assay results showed that silencing of UBE4B expression inhibited proliferation of ACHN (A) and SKRC39 (B) cells. (C, D) Left: representative images of inhibited colony formation in a monolayer culture by silencing UBE4B. Right: colony-forming efficiencies were calculated after 12 days' conventional culture. Measurements were carried out in triplicate, and experiments were repeated three times. Data was presented as mean $\pm S D$. $P$ values were calculated using Student's $t$-test. $* P<0.05$, $* * P<0.01$, and $* * * P<0.00$ I, versus cells transfected with siNC. siNC represents negative control small interfering RNAs. 

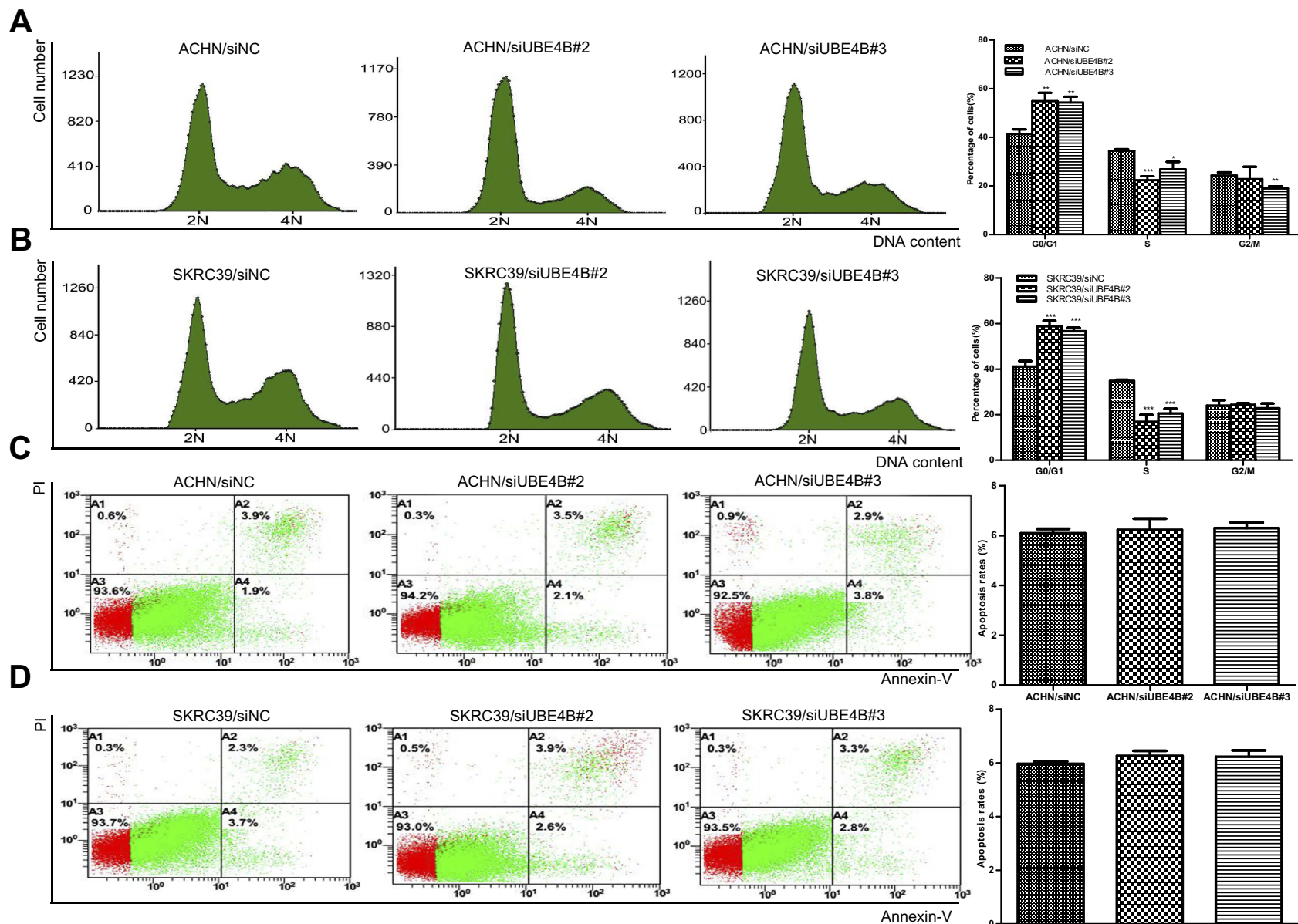

Figure 6 Effects of UBE4B silencing on the cell cycle and apoptosis of of ACHN and SKRC39 cells. (A, B) Effect of UBE4B knockdown on the cell cycle was determined using flow cytometry. UBE4B overexpression caused $G_{0} / G_{1}$ phase arrest in $A C H N(A)$ and SKRC39 (B) cells. (C, D) Effect of UBE4B knockdown on apoptosis of RCC cells was determined with Annexin V-propidium iodide (PI) staining method. Apoptosis rates were not significantly different between $A C H N(C)$ and SKRC39(D) cells transfected with siUBE4B and those transfected with siNC. $P$ values were calculated using Student's $t$-test. $* P<0.05$, $* * P<0.0$ I, and $* * * P<0.00$ I, versus cells transfected with siNC. siNC represents negative control small interfering RNAs.

expression by siRNA could suppress tumor growth and metastasis. Proliferation and colony formation assays confirmed that silencing of UBE4B suppressed RCC cells growth and motility. Several studies had reported similar cellular functions of UBE4B in various types of solid cancers. $^{21,23,24,35}$ Weng et $\mathrm{al}^{23}$ discovered that reduction of UBE4B expression could suppress Nasopharyngeal carcinoma cell growth. Zhang et $\mathrm{al}^{24}$ reported that lowering UBE4B expression by siRNA suppressed the growth and mobility ability of HCC cells. Wu et $\mathrm{al}^{35}$ knocked down UBE4B in wild-type human HCT116 colorectal cancer cells with siRNA and assessed growth ability in a mouse model, and they found that the suppression of UBE4B expression could prohibit tumor formation.

Recently, there is immense interest in restoring p53 activity in tumor cells by inhibiting the murine double minute 2 (MDM2, HDM2 in humans). Many relative studies concur that the interaction between MDM2 and p53 is a primary mechanism for inhibition of the p53 function in cancers retaining wild-type p53, and they found that inhibiting the MDM2 expression could reactivate p53 function, triggering p53dependent cell cycle arrest or apoptosis in tumor cells with functional p53. ${ }^{36-39}$ Blocking the MDM2-p53 interaction to reactivate the $\mathrm{p} 53$ function has been recognized as a promising cancer therapeutic strategy, ${ }^{40,41}$ and a specific inhibitor of MDM2-p53 interaction is still under research. Currently, it has been reported that UBE4B functions as an E4 ligase is essential and required for MDM2 to promote the polyubiquitination and degradation of $\mathrm{p} 53$, thus negatively regulating the stability and function of $\mathrm{p} 53 .{ }^{22,35} \mathrm{Wu}$ et $\mathrm{al}^{35}$ founded that the reduction of UBE4B expression facilitated the ability of p53 to retard BJT fibroblasts in the G1 phase of the cell cycle, which was similar to our finding that lowering UBE4B expression in RCC cells blocked cell cycle progression. Additionally, we 
A

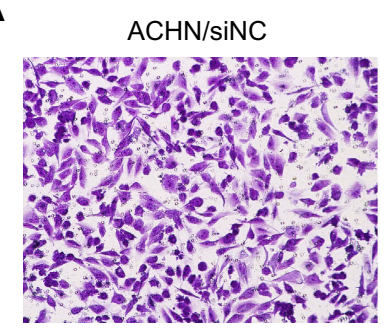

B
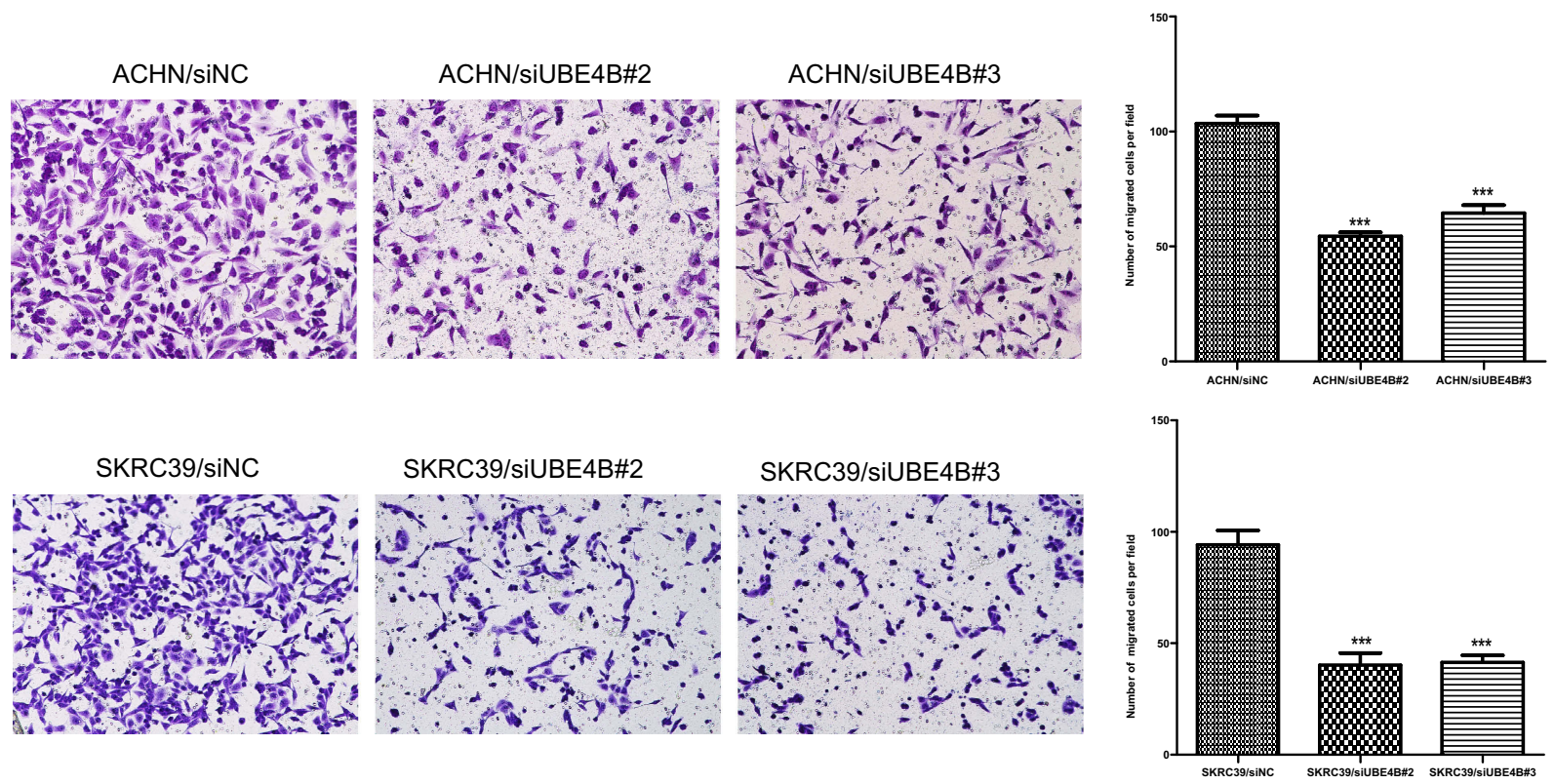

C
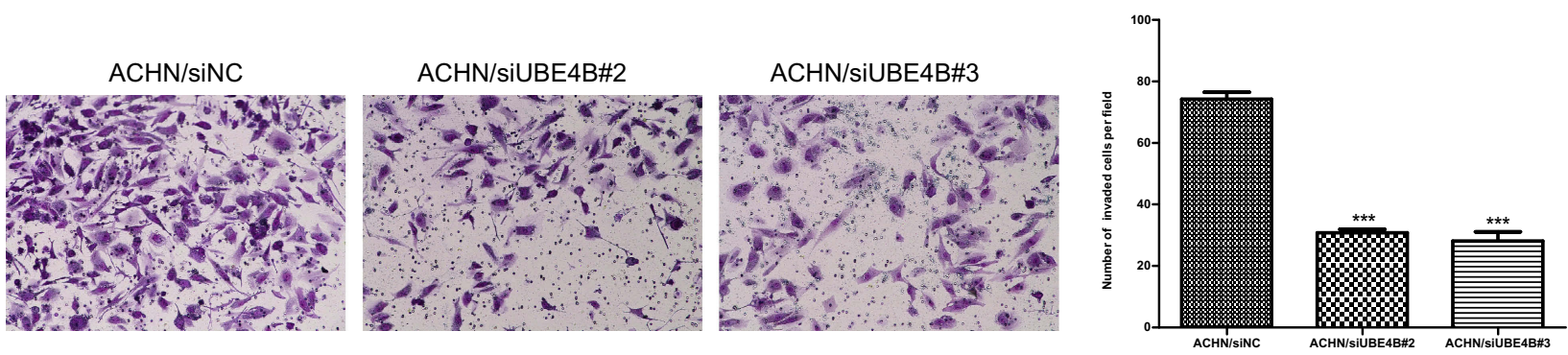

D
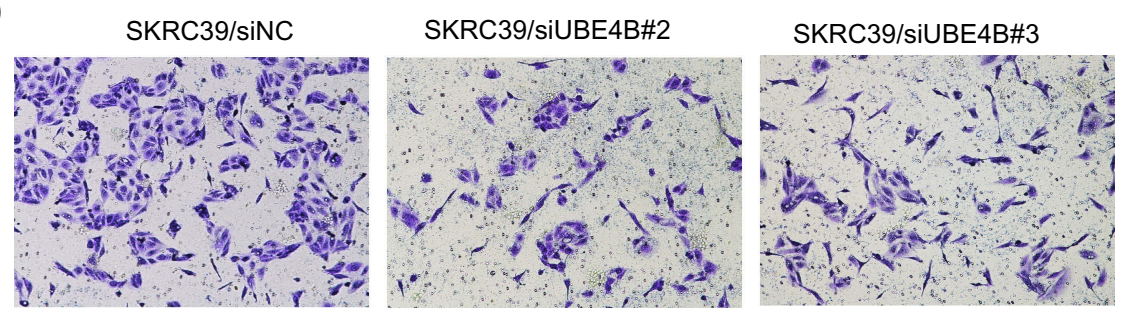

Figure 7 Suppression of RCC cell migration and invasion ability by UBE4B silencing. (A, B) UBE4B knockdown using specific siRNAs inhibited the migration ability of ACHN (A) and SKRC39 (B) cells in a Transwell migration assay. (C, D) UBE4B silencing using specific siRNAs remarkably attenuated the invasion ability of ACHN (C) and SKRC39 (D) cells in a Matrigel invasion assay. Representative images are shown on the left ( $\times 200$ magnification) with quantification of the numbers of cells in ten randomlyselected fields shown on the right. Data was shown as mean $\pm S D$ of three independent experiments. $P$-values were calculated using the Student's $t$-test; $* * P<0.0$ I, $* * * P<0.00$ I, versus cells transfected with siNC. siNC represents negative control small interfering RNAs.

learnt that MDM2-p53 interaction played a specific role in regulating the cell cycle in RCC cells. ${ }^{39}$ Therefore, it is inferred that the function of UBE4B in cell cycle regulation may be involved in the MDM2-p53 pathway in human RCC cells. Our future work will focus on investigating whether UBE4B plays a part in regulating cell cycle-related molecular mechanisms in RCC.

To sum up, this study manifested that UBE4B was overexpressed in RCC, and high UBE4B expression was remarkably related to poor outcome in RCC patients after surgery. Apart from that, cellular function analysis indicated that inhibiting UBE4B expression could restrain RCC cell growth and motility ability, while inducing cell cycle arrest. These results suggested that UBE4B might act as an oncogene in the carcinogenesis of RCC and might serve as an effective indicator to predict OS and a potential biomarker for targeted therapy of RCC patients. 


\section{Ethical Conduct of Research}

Approval for this research was obtained from the SYSUCC Ethics Committee and the patients' informed consent was acquired before the study. Each experimental procedure that involves human specimens was performed based on the ethical standards.

\section{Acknowledgments}

This work was supported by grants from the National Key R\&D Program of China (No. 2018YFC1313400) and the Frontier and Key Technology Innovation Special Grant from the Department of Science and Technology of Guangdong province (No. 2017B020227003).

\section{Author Contributions}

All authors were contributors in conception and design, analysis and interpretation of data. All authors took part in drafting the article or revising it critically for important intellectual content. Every author gave final approval of the version to be published and agreed to be accountable for all aspects of the work.

\section{Disclosure}

The authors report no conflicts of interest in this work.

\section{References}

1. Ljungberg B, Campbell SC, Choi HY, et al. The epidemiology of renal cell carcinoma. Eur Urol. 2011;60(4):615-621. doi:10.1016/j.eururo.2011. 06.049

2. Siegel RL, Miller KD, Jemal A. Cancer statistics, 2015. CA Cancer J Clin. 2015;65(1):5-29. doi:10.3322/caac.21254

3. Itsumi M, Tatsugami K. Immunotherapy for renal cell carcinoma. Clin Dev Immunol. 2011;2010(1740-2522):284581. doi:10.1155/2010/284581

4. A I C, J S L, R A F, et al. Surveillance strategies for renal cell carcinoma patients following nephrectomy. Rev Urol. 2006;8(1):1-7.

5. Girgis AH, Iakovlev VV, Beheshti B, et al. Multilevel whole-genome analysis reveals candidate biomarkers in clear cell renal cell carcinoma. Cancer Res. 2012;72(20):5273-5284. doi:10.1158/0008-5472.can-120656

6. Jemal A, Bray F, Center MM, Ferlay J, Ward E, Forman D. Global cancer statistics. CA Cancer J Clin. 2011;61(2):169-190. doi:10.3322/ caac. 20107

7. Srinivasan R, C J R, Sourbier C, et al. New strategies in renal cell carcinoma: targeting the genetic and metabolic basis of disease. Clin Cancer Res. 2015;21(1):10-17. doi:10.1158/1078-0432.CCR-13-2993

8. Lefeuvre M, Gunduz M, Nagatsuka H, et al. Fine deletion analysis of $1 \mathrm{p} 36$ chromosomal region in oral squamous cell carcinomas. J Oral Pathol Med. 2009;38(1):94-98. doi:10.1111/j.1600-0714.2008.00666.x

9. Mammen AL, Mahoney JA, St Germain A, et al. A novel conserved isoform of the ubiquitin ligase UFD2a/UBE4B is expressed exclusively in mature striated muscle cells. PLoS One. 2011;6(12):e28861. doi:10.1371/journal.pone. 0028861

10. Koegl M, Hoppe T, Schlenker S, Ulrich HD, Mayer TU, Jentsch S. A novel ubiquitination factor, E4, is involved in multiubiquitin chain assembly. Cell. 1999;96(5):635-644. doi:10.1016/S00928674(00)80574-7
11. Jordan VK, Zaveri HP, Scott DA. 1p36 deletion syndrome: an update. Appl Clin Genet. 2015;8:189-200. doi:10.2147/TACG.S65698

12. Nussinov R, Tsai CJ, Liu J. Principles of allosteric interactions in cell signaling. J Am Chem Soc. 2014;136(51):17692-17701. doi:10.1021/ ja510028c

13. Loveless TB, Topacio BR, Vashisht AA, et al. DNA damage regulates translation through $\beta$-TRCP targeting of CReP. PLoS Genet. 2015;11(6):e1005292. doi:10.1371/journal.pgen.1005292

14. Pomerantz JH, Blau HM. Tumor suppressors: enhancers or suppressors of regeneration? Development. 2013;140(12):2502-2512. doi: $10.1242 /$ dev. 084210

15. Brown CJ, Lain S, Verma CS, Fersht AR, Lane DP. Awakening guardian angels: drugging the p53 pathway. Nat Rev Cancer. 2009;9(12):862-873. doi:10.1038/nrc2763

16. Soussi T. The p53 pathway and human cancer. Brit J Surg. 2005;92 (11):1331-1332. doi:10.1002/bjs.5177

17. Wu H, Leng RP. UBE4B, a ubiquitin chain assembly factor, is required for MDM2-mediated p53 polyubiquitination and degradation. Cell Cycle. 2011;10(12):1912-1915. doi:10.4161/cc.10.12.15882

18. Shi D, Pop MS, Kulikov R, Love IM, Kung AL, Grossman SR. CBP and p300 are cytoplasmic E4 polyubiquitin ligases for p53. Proc Natl Acad Sci USA. 2009;106(38):16275-16280. doi:10.1073/pnas.0904305106

19. Pant V, Lozano G. Limiting the power of p53 through the ubiquitin proteasome pathway. Genes Dev. 2014;28(16):1739-1751. doi:10.1101/ gad.247452.114

20. Du C, Wu H, Leng RP. UBE4B targets phosphorylated $\mathrm{p} 53$ at serines 15 and 392 for degradation. Oncotarget. 2016;7(3):2823-2836. doi:10.18632/oncotarget.6555

21. Zhang Y, Lv Y, Zhang Y, Gao H. Regulation of p53 level by UBE4B in breast cancer. PLoS One. 2014;9(2):e90154. doi:10.1371/journal. pone. 0090154

22. Heuze ML, Lamsoul I, Moog-Lutz C, Lutz PG. Ubiquitin-mediated proteasomal degradation in normal and malignant hematopoiesis. Blood Cells Mol Dis. 2008;40(2):200-210. doi:10.1016/j.bcmd.2007.07.011

23. Weng $\mathrm{C}, \mathrm{Chen} \mathrm{Y}, \mathrm{Wu} \mathrm{Y}$, et al. Silencing UBE4B induces nasopharyngeal carcinoma apoptosis through the activation of caspase 3 and $\mathrm{p} 53$. Onco Targets Ther. 2019;12:2553-2561. doi:10.2147/OTT.S196132

24. Zhang XF, Pan QZ, Pan K, et al. Expression and prognostic role of ubiquitination factor E4B in primary hepatocellular carcinoma. Mol Carcinog. 2016;55(1):64-76. doi:10.1002/mc.22259

25. De Vivar Chevez AR, Finke J, Bukowski R. The role of inflammation in kidney cancer. Adv Exp Med Biol. 2014;816:197-234. doi:10.1007/ 978-3-0348-0837-8_9

26. Escudier B, Eisen T, Porta C, et al. Renal cell carcinoma: ESMO clinical practice guidelines for diagnosis, treatment and follow-up. Ann Oncol. 2012;23(7):65-71. doi:10.1093/annonc/mds227

27. Eble JN, Sauter G, Epstein JI, Sesterhen IA. Worle Health Organization Classification of Tumour. Pathology and Genetics of Tumors of the Urinary Systerm and Male Genital Organs. Lyon: IARC Press; 2004.

28. Fuhrman SA, Lasky LC, Limas C. Prognostic significance of morphologic parameters in renal cell carcinoma. Am J Surg Patho. 1982;6(7):655-663. doi:10.1097/00000478-198210000-00007

29. Edge SB, Byrd DR, Compton CC, Fritz AG, Greene FL, Trotti A. AJCC Cancer Staging Manual (7th Ed). New York: Springer; 2010.

30. Huang XQ, Zhou ZQ, Zhang XF, et al. Overexpression of SMOC2 attenuates the tumorigenicity of hepatocellular carcinoma cells and is associated with a positive postoperative prognosis in human hepatocellular carcinoma. J Cancer. 2017;8(18):3812-3827. doi:10.7150/jca.20775

31. Zage PE, Sirisaengtaksin N, Liu Y, et al. UBE4B levels are correlated with clinical outcomes in neuroblastoma patients and with altered neuroblastoma cell proliferation and sensitivity to epidermal growth factor receptor inhibitors. Cancer. 2013;119(4):915-923. doi:10.1002/cncr.27785

32. Woodfield SE, Guo RJ, Liu Y, et al. Neuroblastoma patient outcomes, tumor differentiation, and ERK activation are correlated with expression levels of the ubiquitin ligase UBE4B. Genes Cancer. 2016;7 (1-2):13-26. doi:10.18632/genesandcancer.97 
33. Ha US, Lee KW, Jung JH, et al. Renal capsular invasion is a prognostic biomarker in localized clear cell renal cell carcinoma. Sci Rep. 2018;8(1):202-210. doi:10.1038/s41598-017-18466-9.

34. Singh RR, Murugan P, Patel LR, et al. Intratumoral morphologic and molecular heterogeneity of rhabdoid renal cell carcinoma: challenges for personalized therapy. Mod Pathol. 2015;28(9):1225-1235. doi:10.1038/ modpathol.2015.68

35. Wu H, Pomeroy SL, Ferreira M, et al. UBE4B promotes Hdm2-mediated degradation of the tumor suppressor p53. Nat Med. 2011;17(3):347-355. doi: $10.1038 / \mathrm{nm} .2283$

36. De Rozieres S, Maya R, Oren M, Lozano G. The loss of mdm2 induces p53 mediated apoptosis. Oncogene. 2000;19(13):1691-1697. doi:10.1038/sj.onc.1203468

37. Safiran YJ, Oberoi P, Kenten JH, Philliphs AC, Weissman AM, Vousden KH. Small molecule inhibitors of HDM2 ubiquitin ligase activity stabilize and activate p53 in cells. Cancer Cell. 2005; 7:547-559. doi:10.1016/j.ccr.2005.04.029
38. Ringshausen I, O'Shea CC, Finch AJ, Swigart LB, Evan GI. $\mathrm{Mdm} 2$ is critically and continuously required to suppress lethal p53 activity in vivo. Cancer Cell. 2006;10:501-514. doi:10.1016/j. ccr.2006.10.010

39. Warburton HE, Brady M, Vlatkovic' N, Linehan WH, Parsons K, Boyd MT. p53 regulation and function in renal cell carcinoma. Cancer Res. 2005;65(15):6498-6503. doi:10.1158/0008-5472.CAN05-0017

40. Chène P. Inhibiting the p53-MDM2 interaction: an important target for cancer therapy. Nat Rev Cancer. 2003;3(2):102-109. doi:10.1038/ nrc991

41. Shangary S, Wang S. Targeting the MDM2-p53 interaction for cancer therapy. Clin Cancer Res. 2008;14(17):5318-5324. doi:10.1158/ 1078-0432.CCR-07-5136

\section{Publish your work in this journal}

OncoTargets and Therapy is an international, peer-reviewed, open access journal focusing on the pathological basis of all cancers, potential targets for therapy and treatment protocols employed to improve the management of cancer patients. The journal also focuses on the impact of management programs and new therapeutic agents and protocols on patient perspectives such as quality of life, adherence and satisfaction. The manuscript management system is completely online and includes a very quick and fair peer-review system, which is all easy to use. Visit http://www.dovepress.com/ testimonials.php to read real quotes from published authors. 